\title{
PROPOSTA DE JOGO DA MEMÓRIA PARA ANÁLISE DE DESEMPENHO COGNITIVO DE DEFICIENTES INTELECTUAIS
}

\author{
Letícia Gonçalves Segatto*, Mariana Cardoso Melo* \\ Universidade de Uberaba, Uberlândia, Brasil. \\ e-mail: leticiasegatto1@gmail.com
}

\begin{abstract}
Resumo: A proposta do projeto é avaliar o potencial do Jogo da Memória como tecnologia assistiva para alunos com deficiência intelectual, especialmente um jogo que trabalhe com a memória e que estimule a prática de exercícios físicos. Para tanto, foi desenvolvido um jogo, denominado Jogo da Memória, sendo disposto um notebook e um gabinete de MDF no formato trapezoidal com quatro botoeiras de fliperama nas cores: amarela, azul, verde e vermelha. Será apresentada no monitor uma sequência de imagens coloridas, cada uma terá uma cor específica: ou amarela, azul, verde ou vermelha. Após a apresentação, o participante deverá selecionar nas botoeiras a sequência de cores apresentadas e, para que não haja dúvidas, as cores selecionadas serão indicadas no monitor. Caso o jogador acerte, será mostrada a seguinte mensagem: "Você acertou!". Caso a sequência esteja errada, será mostrada a atividade a ser realizada. Contudo, o objetivo é analisar a contribuição do Jogo da Memória para o desenvolvimento cognitivo dos alunos com deficiência intelectual, para que os mesmos desenvolvam também habilidades que ainda não tinha sido aprendido por eles antes de forma convencional.
\end{abstract}

Palavras-chave: Jogo da Memória, Tecnologia Assistiva, Deficiência Intelectual.

Abstract: The main objective of this work is to evaluate the potential of a memory game as an assistive technology for students with intelectual defficiency, that involves the memory and that stimulates the practice of physical activities. For this, it was developed a game, that demands a computer and a wood box in trapezoidal shape with four pushbuttons in the following colors: yellow, blue, green and red.It is presented to the volunteer, a sequence of colored images, that can be yellow, blue, green or red. After the presentation, the participant should select the pushbutton with the same color of the sequence presented, and the selection is presented on the screen. If the player selects correctly, it will be showed the message "You are right!". if the sequence is wrong, it will be showed a physical activity to be done by the participants. After the test, it will be analised the potential of the game to the cognitive development of the students with intelectual defficiency.

Keywords: Memory Game, Assistive Technology, Intelectual defficiency.

\section{Introdução}

As limitações do indivíduo com deficiência intelectual tendem a tornar uma barreira quando se trata de educação inclusiva. Uma vez que alunos com deficiência intelectual podem apresentar dificuldades nas habilidades que exigem atenção, memorização e compreensão de conceitos que são elementos fundamentais para aprendizagem escolar em geral. [1,4]

Uma forma de amenizar as barreiras causadas pela deficiência seria o desenvolvimento de Tecnologias Assistivas, que consistem desde recursos com pouca tecnologia até sofisticados programas de computadores. $[2,4]$. A terminologia "Tecnologia Assistiva" foi oficializada pelo Comitê de Ajudas Técnicas da Subsecretaria Nacional de Promoção de Pessoa com deficiência e é considerada como uma área interdisciplinar do conhecimento, que engloba produtos, recursos, metodologias, estratégias e práticas para promover a funcionalidade. Esta relacionada à atividade e participação de pessoas com deficiência intelectual, para lhes proporcionar qualidade de vida e inclusão social. [3]

Os jogos e brincadeiras são estratégias metodológicas práticas para os alunos desenvolverem habilidades cognitivas e facilitar na construção de conhecimento. Dessa forma, o jogo possibilita ao deficiente intelectual aprender de acordo com seu ritmo e suas capacidades, além de propiciar a integração com mundo por meio de relações e vivências. [5]

Sendo assim, este projeto insere-se neste contexto explorando a utilização do Jogo da Memória que trabalhará habilidades mentais necessárias para obtenção do conhecimento, como memorização, atenção e capacidade de resolução de problemas para os alunos com deficiência intelectual.

\section{Desenvolvimento do projeto}

Inicialmente, devem ser obtidas informações básicas sobre o voluntário, para configuração dos parâmetros do jogo, como nome, idade, quantidade de vezes que o voluntário executará o jogo e o nível do mesmo.

O jogo proposto possui três níveis diferentes, que será definido de acordo com o grau de dificuldade de cada jogador. Posteriormente, será avaliada a quantidade de vezes que um jogador precisou executar 
um determinado nível, para analisar a evolução cognitiva do voluntário.

No primeiro e segundo nível, aparecerão para o jogador três imagens com cores e categorias diferentes, em que será exibida na tela uma imagem por vez. O que diferencia ambos os níveis é o tempo de memorização para cada imagem. No primeiro nível, a imagem fica disponível em um tempo de dez segundos cada, já no segundo, o tempo é de sete segundos cada. No terceiro nível, é acrescentada uma cor diferente, aparecendo para o jogador quatro imagens por vez, com cores e categorias diferentes, e o tempo de memorização para cada figura é de cinco segundos.

O jogo proposto é composto por 38 categorias e 128 imagens. As primeiras 24 categorias são dedicadas aos níveis um e dois. Em cada categoria tem três imagens diferentes, nas cores amarela, azul e verde, totalizando 72 imagens sorteadas pelo software. As 14 últimas categorias são dedicadas ao terceiro nível, totalizando 56 figuras distintas. Para cada categoria, há quatro imagens diferentes, nas cores amarelo, azul, verde e vermelho. Para que jogo proposto não fosse repetitivo, foi inserida uma função no programa que sorteia as categorias e as cores, para cada nível. Ou seja, a sequência de cores apresentadas a cada jogo irá mudar.

As imagens de cada categoria estabelecem relação entre si. Foram selecionados objetos do cotidiano, animais silvestres, domésticos e exóticos, itens escolares, meios de transportes, o alfabeto oficial da língua portuguesa, diversos modelos de brinquedos, frutas, verduras, legumes, doces e algumas figuras geométricas.

Após a apresentação, o programa irá solicitar que o participante selecione nas botoeiras a sequência de cores apresentada..

O jogador será informado por meio de uma mensagem qual a cor da botoeira que o mesmo está selecionando. Caso a sequência de cores apresentadas corresponderem com a sequência selecionada nas botoeiras, aparecerá a seguinte mensagem, "Você acertou". Se, ao finalizar a seleção de cores nas botoeiras, a sequência não for correta, será apresentada no monitor qual atividade o jogador terá que executar.

A inserção de prática de exercícios físicos e o incentivo a momentos de descontração serão exploradas caso o jogador não acerte a sequência das cores apresentadas. O objetivo é desenvolver a consciência corporal, através de atividades como: correr o mais rápido que conseguir; chutar a bola forte; equilibre em uma perna só; gire em uma perna só; faça um alongamento; escolher um amigo para apostar uma corrida; e incentivar momentos de descontração como: cante a música que mais gosta; imite algum animal; abrace o colega mais próximo ou dance.

\section{Resultados}

A Figura 1 mostra representa o protótipo do jogo desenvolvido com a caixa das botoeiras coloridas e o software.

Figura 1 - Protótipo do Jogo da Memória.

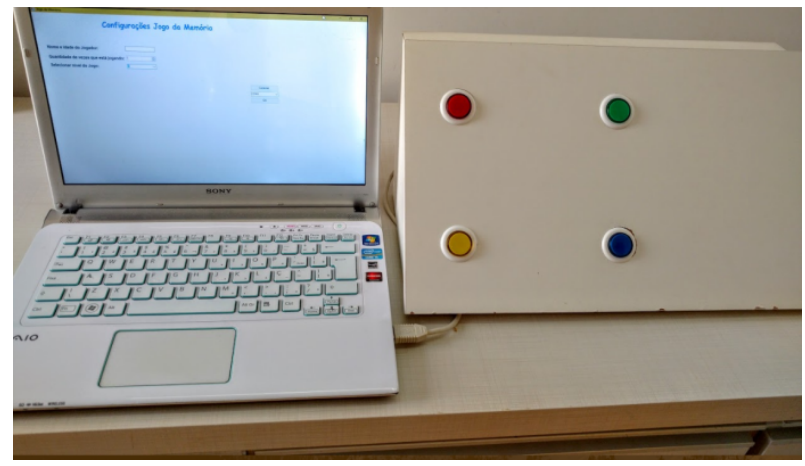

Inicialmente, aparecerão as configurações de parâmetros do jogo proposto, conforme a Figura 2:

Figura 2 - Layout configurações de parâmetros do jogo proposto.

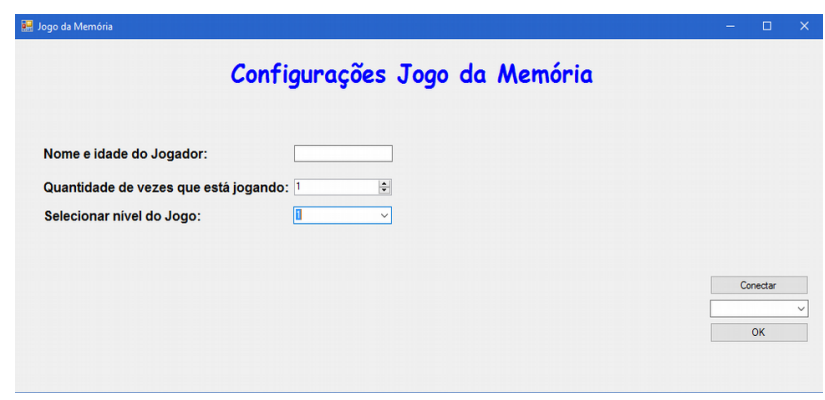

Será exemplificado a seguir, caso o nível 1 seja selecionado, uma sequência de imagens que poderão aparecer no jogo proposto. A primeira imagem (Figura 3) - corresponde à cor azul e ficará disponível por 10 segundos. Após a finalização deste tempo, ela ficará indisponível. Aparecerá a segunda imagem.

Figura 3 - Exemplo de primeira imagem apresentada correspondente ao nível 1 .

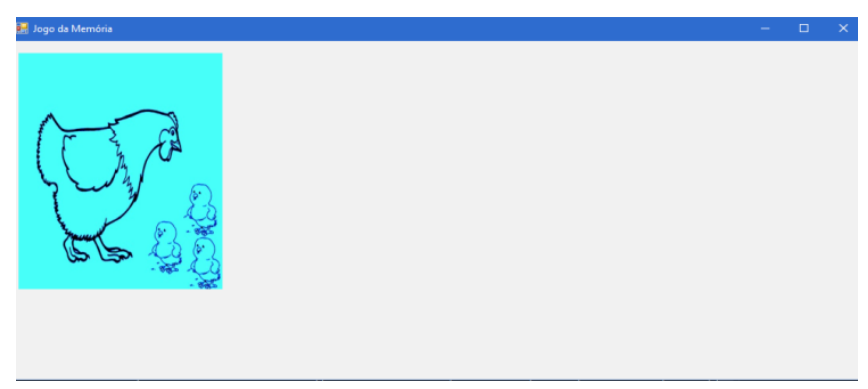

A segunda imagem (Figura 4) corresponde à cor verde e ficará disponível por 10 segundos. Após a 
finalização deste tempo, ela ficará indisponível. Aparecerá a terceira imagem.

Figura 4 - Exemplo de segunda imagem apresentada correspondente ao nível 1.

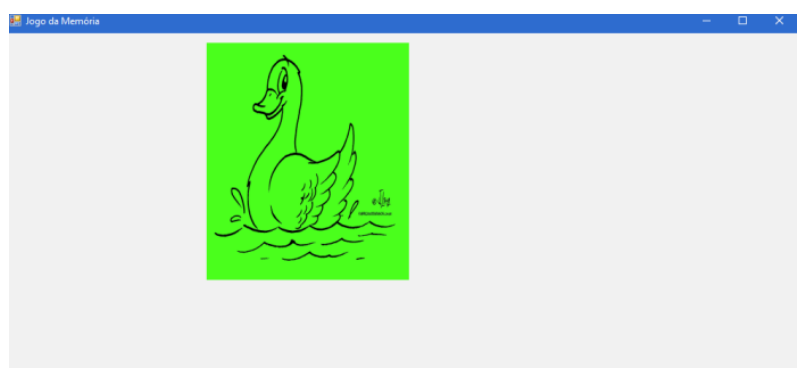

A terceira imagem (Figura 5) corresponde à cor amarela e ficará disponível por 10 segundos. Após a finalização deste tempo, ela ficará indisponível.

Figura 5 - Exemplo terceira imagem apresentada correspondente ao nível 1.

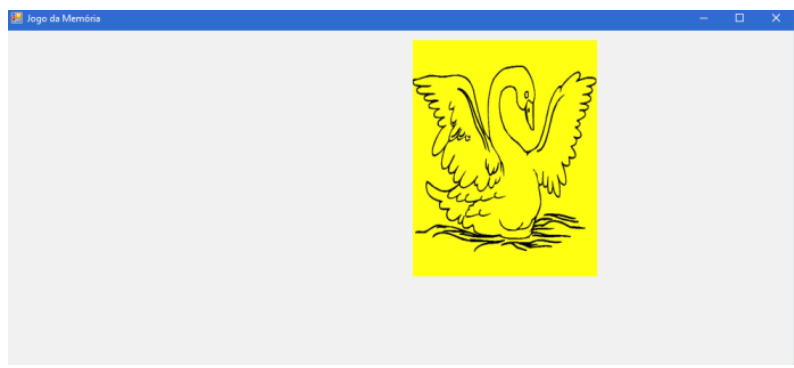

Após a finalização do tempo de 10 segundos da terceira imagem, aparecerá a mensagem mostrada a seguir na Figura 6:

Figura 6 - Mensagem solicitando que o jogador aperte a sequência que lhe fora apresentada.

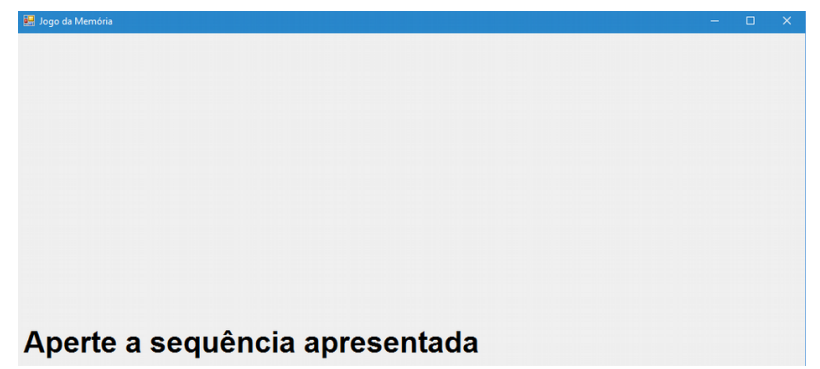

Assim que aparecer a seguinte mensagem da Figura 6, o jogador pode iniciar o jogo. De acordo com a exemplificação, as sequências corretas das botoeiras que o voluntário deve acionar são mostradas nas Figuras 7,8 e 9 por um voluntário.
Figura 7 - Primeira botoeira a ser selecionada, corresponde à primeira imagem apresentada no nível 1 .

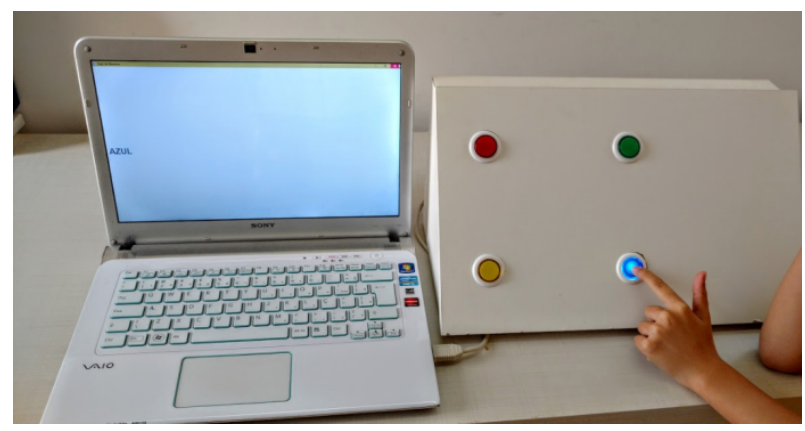

Figura 8 - Segunda botoeira a ser selecionada, corresponde à primeira imagem apresentada no nível 1

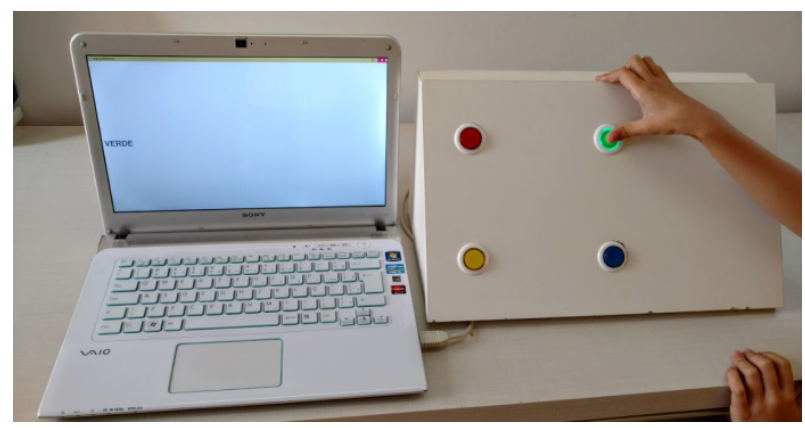

Figura 9 - Terceira botoeira a ser selecionada, corresponde à primeira imagem apresentada no nível 1

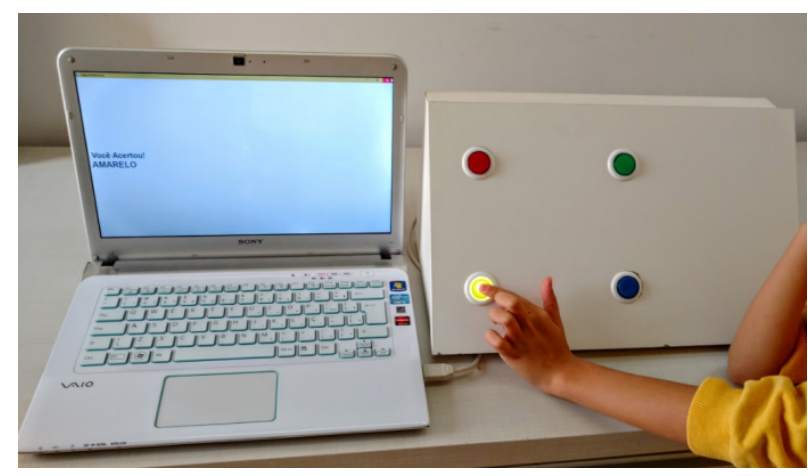

\section{Discussões}

O Jogo da Memória foi utilizado na Associação de Apoio ao Deficiente no bairro Liberdade, localizado em Uberlândia/Minas Gerais, (AADL). Ao todo, seis alunos deficientes intelectuais, que não possuem nenhum distúrbio visual, como o daltonismo, participaram da pesquisa. Cada sessão teve aproximadamente duração de 1horas e 30 minutos, sendo que em média cada voluntário jogou doze vezes.

A Tabela 1 apresenta as características dos voluntários. A princípio, foram escolhidos três alunos do sexo feminino e três do sexo masculino com pequena variação de idade. 
Tabela 1: Características dos voluntários.

\begin{tabular}{lll}
\hline Voluntários & Sexo & Idade \\
\hline Voluntário 1 & Masculino & 40 anos \\
Voluntário 2 & Feminino & 28 anos \\
Voluntário 3 & Feminino & 28 anos \\
Voluntário 4 & Masculino & 37 anos \\
Voluntário 5 & Feminino & 49 anos \\
Voluntário 6 & Masculino & 39 anos \\
\hline
\end{tabular}

No primeiro momento, foi explicado pausadamente como o jogo proposto iria funcionar, conversando a respeito das cores das botoeiras que compõe o gabinete MDF e apresentando algumas imagens que estão presentes no programa.

A Tabela 2 mostra os resultados que, inicialmente, foram obtidos com o Jogo da Memória, descrevendo, por voluntário, o indicativo de quantas vezes o mesmo errou o respectivo nível para avançar o próximo.

Tabela 2 - Quantidade de erros dos voluntários em cada nível.

\begin{tabular}{lc|c|c}
\hline \multirow{2}{*}{ Voluntários } & \multicolumn{3}{c}{ Erros por níveis } \\
\cline { 2 - 4 } & Nível 1 & Nível 2 & Nível 3 \\
\hline Voluntário 1 & 3 & 2 & 4 \\
Voluntário 2 & 3 & 3 & 8 \\
Voluntário 3 & 2 & 1 & 4 \\
Voluntário 4 & 3 & 4 & 3 \\
Voluntário 5 & 3 & 2 & 5 \\
Voluntário 6 & 1 & 1 & 3
\end{tabular}

Os voluntários 1, 2, 3 e 6 obtiveram melhor desempenho nos dois primeiros níveis. Os voluntários 4 e 5 mostraram dificuldades para assimilar as cores que lhes eram apresentadas com as dispostas no gabinete MDF. Com o jogo em desenvolvimento, ambos ficaram atentos à execução dos outros alunos e melhoraram a desempenho. Já no terceiro nível, apenas os voluntários 4 e 6 demonstraram menos dificuldade para executá-lo.

Foram feitas algumas observações pela pedagoga da instituição a respeito do comportamento e desenvolvimento dos alunos durante o jogo. Alguns voluntários demonstraram timidez no início do jogo, mas de acordo que foram aparecendo as atividades e exercícios para todos realizarem, caso errassem, houve um maior entrosamento dos mesmos.

No primeiro momento, alguns voluntários pressionavam a primeira botoeira correspondente à última que cor que lhe era apresentada. Mas, ficaram atentos quando os outros alunos que obtiveram um melhor desempenho inicialmente jogavam e, então, obtiveram êxito nas próximas execuções. Demonstravam interesse em jogar novamente caso errassem.

\section{Conclusões}

Com o desenvolvimento do jogo proposto, foi possível obter indícios do potencial do Jogo da Memória como tecnologia assistiva e a contribuição do mesmo para o desenvolvimento cognitivo de alunos com deficiência intelectual. Outra contribuição do jogo proposto foram os momentos de interação que os voluntários tiveram quando era solicitado a eles realizar alguma atividade física.

Para a pesquisa inicial, foi realizado um experimento piloto para verificar a adequação dos alunos com deficiência intelectual no jogo proposto. Desse modo, mesmo que os resultados obtidos correspondem somente a duas sessões, como trabalho futuro será realizado mais sessões, avaliando o desenvolvimento dos voluntários baseado nas primeiras.

Embora a proposta inicial do jogo proposto não abrangeu deficientes intelectuais daltônicos, será realizada uma adaptação, incluindo som no jogo. Informando para o jogador a cor da imagem que está sendo apresentada e ele poderá testar no protótipo qual a cor da respectiva botoeira, auxiliando o mesmo a memorizar qual é a cor de cada botoeira no próximo momento em que irá jogar.

Apesar dos jogos serem considerados um recurso eficaz para facilitação do aprendizado, o acesso às literaturas similares a respeito de jogos para deficientes intelectuais que trabalhassem a memória foi limitado.

\section{Agradecimentos}

À orientadora Mariana Cardoso Melo pelos ensinamentos e por toda contribuição no projeto À professora Luciene Chagas de Oliveira, pelas contribuições importantes para o desenvolvimento da programação. Ao Sr. Lucas Matheus, pela ajuda na confecção do protótipo, além de contribuir com a melhoria na interface do jogo. A diretora e pedagoga, Fátima Conceição Ferreira, que permitiu que o jogo proposto fosse realizado na instituição, e aos voluntários, que foram de fundamental importância para o desenvolvimento inicial da pesquisa.

\section{Referências}

[1] WESTWOOD, P. What teachers need to know about students with disabilities. ACER Press, 2009.

[2] SCHIMER, C. R. et al. Atendimento Educacional Especializado: Deficiência Física . São Paulo : MEC/ SEESP, 2007. 130p.

[3] BERSCH, R. Introdução à Tecnologia Assistiva. Porto Alegre, 2013.

[4] MALAQUIAS, F. F. O. Realidade Virtual como Tecnologia Assistiva Para Alunos com Deficiência Intelectual

[5] MAFRA, S. R. C. et al. O Lúcido na Prática de Alunos Deficientes Intelectuais. Disponível em http://www.diaadiaeducacao.pr.gov.br/portals/pde/arqui vos/2444-8.pdf . Acesso em: 05 de agosto 2016. 